\title{
61. MAGNETIC INTENSITY VARIATIONS IN SEDIMENT CORES FROM LEG $128^{1}$
}

\author{
Yozo Hamano ${ }^{2}$ and Klaus A. O. Krumsiek ${ }^{3}$
}

\begin{abstract}
Variations of the intensity of magnetization in the sediment cores from Sites 798 and 799 were examined. Closely correlated variations in the magnetic intensity enabled estimation of the relative change of the sedimentation rate between the two sites. A high sedimentation rate of more than $30 \mathrm{~cm} / 1,000 \mathrm{yr}$ was inferred for about $550,000 \mathrm{yr}$ ago at Site 799 . The sedimentation rate was used to compare the distribution of volcanic ash layers at two sites.
\end{abstract}

\section{INTRODUCTION}

During Ocean Drilling Program (ODP) Leg 128, sediment cores were obtained from Sites 798 and 799 . At Site $798\left(37.04^{\circ} \mathrm{N}, 134.80^{\circ} \mathrm{E}\right)$, Holes 798A, 798B and 798C were cored with the advanced hydraulic piston corer (APC) to depths of 142.5, 142.6, and $120.1 \mathrm{~m}$ below seafloor (mbsf), respectively. At Site $799\left(39.22^{\circ} \mathrm{N}, 133.87^{\circ} \mathrm{E}\right), \mathrm{APC}$ cores were taken to a depth of $184.1 \mathrm{mbsf}$ (see Ingle, Suyehiro, von Breymann, et al., 1990). The APC cores possess a very stable remanence and reveal detailed records of the geomagnetic field during the Pliocene-Pleistocene period (Hamano et al., this volume). The sedimentation rate at these sites during the Pliocene-Pleistocene period can be estimated from the magnetic polarity boundaries in these cores and biostratigraphy. At Site 798, the sedimentation rate has been relatively constant at a high value of $110 \mathrm{~m} / \mathrm{m}$.y. for the last $2 \mathrm{~m}$.y. On the other hand, the sedimentation rate at Site 799 abruptly increased at the Brunhes/Matuyama polarity boundary. The sedimentation rate before this polarity boundary was as low as $30 \mathrm{~m} / \mathrm{m}$.y. since $2 \mathrm{~m}$.y. ago. The sedimentation rate increased to a high value of more than $120 \mathrm{~m} / \mathrm{m}$.y. after the Matuyama/Brunhes polarity transition.

The sedimentation rate mentioned here has a kind of averaged nature, because the check points for the rate are generally separated in time by more than several hundreds of thousands of years. In the present paper, we attempt to obtain a more detailed record of variation in the relative sedimentation rate from a comparison of the intensity variations of the magnetization in the sediments obtained from the Leg 128 Japan Sea holes. Because of the depth limitation of the APC cores, we compare mainly the variations during the Brunhes Epoch (last $700,000 \mathrm{yr}$ ).

\section{ANALYSIS}

During Leg 128, the natural remanent magnetization (NRM) of the APC cores from Hole 798A was measured from the top of the hole to the bottom at $142.5 \mathrm{mbsf}$ and that of the cores from Hole $798 \mathrm{C}$ was measured from the top to the total depth of $120.1 \mathrm{mbsf}$. Cores from Hole 798B were measured from $65 \mathrm{mbsf}$ to the bottom of the hole. The measurements were made at several steps of alternating field (AF) demagnetization up to $15 \mathrm{mT}$. For all of the cores, an AF field of $10 \mathrm{mT}$ was sufficient to clean up the secondary component of the magnetization. The entire APC cored section from Hole 799A was measured by using a pass-through cryogenic magnetometer with the several steps of the AF field. Although the magnetization of the cores from Hole 799A is less stable than that of the cores from Site 798, a

'Tamaki, K., Suyehiro, K., Allan, J., McWilliams, M., et al., 1992. Proc. ODP, Sci. Results, 127/128, Pt. 2: College Station, TX (Ocean Drilling Program).

${ }^{2}$ Geophysical Institute, Faculty of Science, University of Tokyo, Tokyo 113, Japan.

${ }^{3}$ Geologisches Institut, Universitat Köln, Köln, Germany. demagnetization field of $15 \mathrm{mT}$ was sufficient to reveal the polarity sequences during the Pliocene-Pleistocene period.

Variations of the intensity of magnetization during the Brunhes normal Epoch observed in the APC cores from Holes 798A, 798C, and 799A are compared in Figure 1. Based on the mud-line measurements, the top of the cored sediment section from Hole 798A was estimated to be several meters below the mud line. Hence, the data for Hole 798A were shifted by $4 \mathrm{~m}$ in Figure 1 . The right-hand side of the plot in each hole corresponds to the depth of the Brunhes/ Matuyama polarity boundary observed from the inclination and declination data. In this depth scale, the intensity variations from the three holes are well correlated. Holes 798A and 798C, are within $40 \mathrm{~m}$ of each other, but the distance between Site 798 and Site 799 is about $300 \mathrm{~km}$. Therefore, the similar pattern of the variation in intensity suggests that it is not a local effect.

Figure 2 is a comparison of the variations of the magnetic susceptibility in the three holes as a function of depth, which indicates variations in the concentration of magnetic minerals in the sediments. The depth range in Figure 2 is the same as in Figure 1. As is evident in Figure 2, the amplitude of the susceptibility variations is much smaller than that of the variation in magnetic intensity. In addition, the various features of the depth variation of the magnetic intensity are not observed in the variation of the magnetic susceptibility. In Figure 1, short scale variations of the magnetic intensity with wavelengths of several meters to $10 \mathrm{~m}$ are observed, whereas such variation is not apparent in the plot in Figure 2.

Sedimentary sequence of Unit I at Site 798 (top of the section to $220 \mathrm{mbsf}$ ) is characterized by a rhythmic alternation of dark- and light-colored sediments on a size scale of decimeters to meters. On a larger scale, however, the sedimentation rate seems constant for the last 2 m.y.. On the other hand, the sedimentation rate at Site 799 seems to have fluctuated more. Sediments in some sections (10.0-11.2 and $40-79$ mbsf) have been affected by soft-sediment deformation. Turbidity flow structures were also detected in various parts of the sedimentary section. Hence, we can assume that the sedimentary environment at Hole 798A was more stable than that at Site 799. We tried to observe the change in sedimentation conditions at Site 799 relative to that at Site 798 , assuming that the sedimentation rate at Site 798 had been stable during the last $700,000 \mathrm{yr}$.

The comparison of variations in the magnetic intensity at the three holes is on approximately the same time scale in Figure 1, because the overall sedimentation rate for these three holes is similar from the depth of the Brunhes/Matuyama boundary to the top of the sediment in each hole. Before this polarity boundary, the sedimentation rate at Site 799 was much slower than that at Site 798 . Hence, the intensity variations before the Brunhes/Matuyama polarity boundary should be compared using different depth scales. An example of the comparison for a section immediately below the Brunhes/Matuyama boundary is shown in Figure 3, where the depth scale is adjusted by the onset and the termination of the Jaramillo normal event. The depth range 
798A

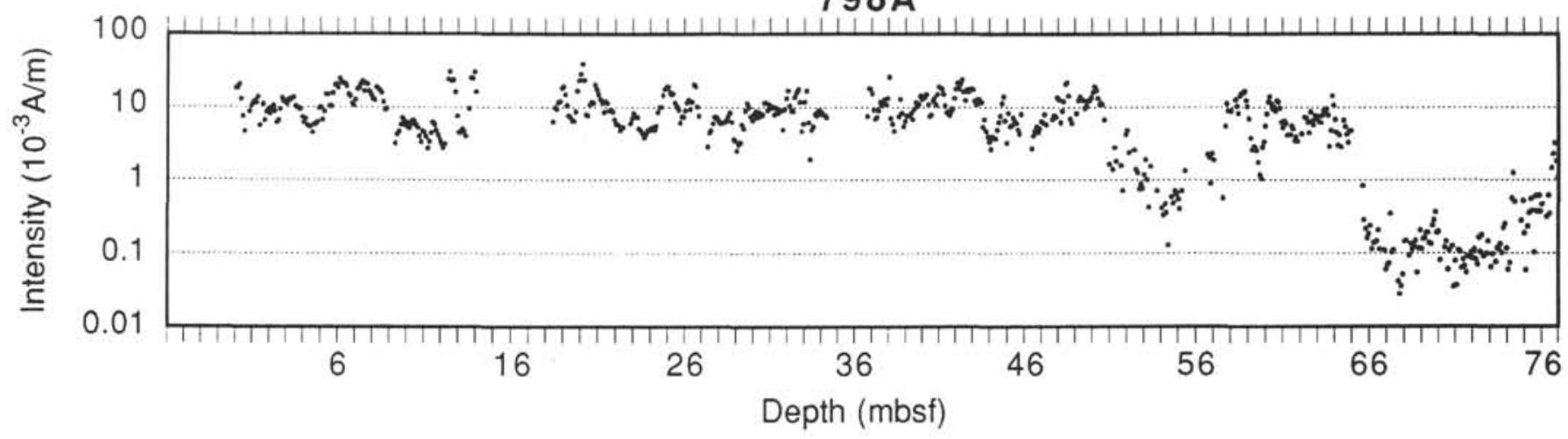

$798 \mathrm{C}$

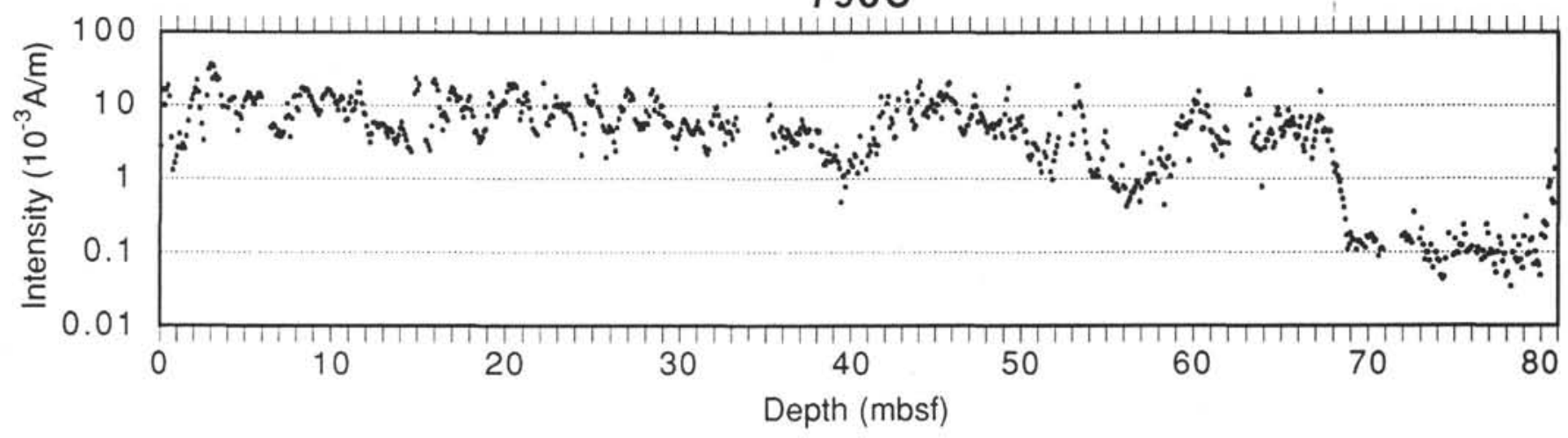

799A

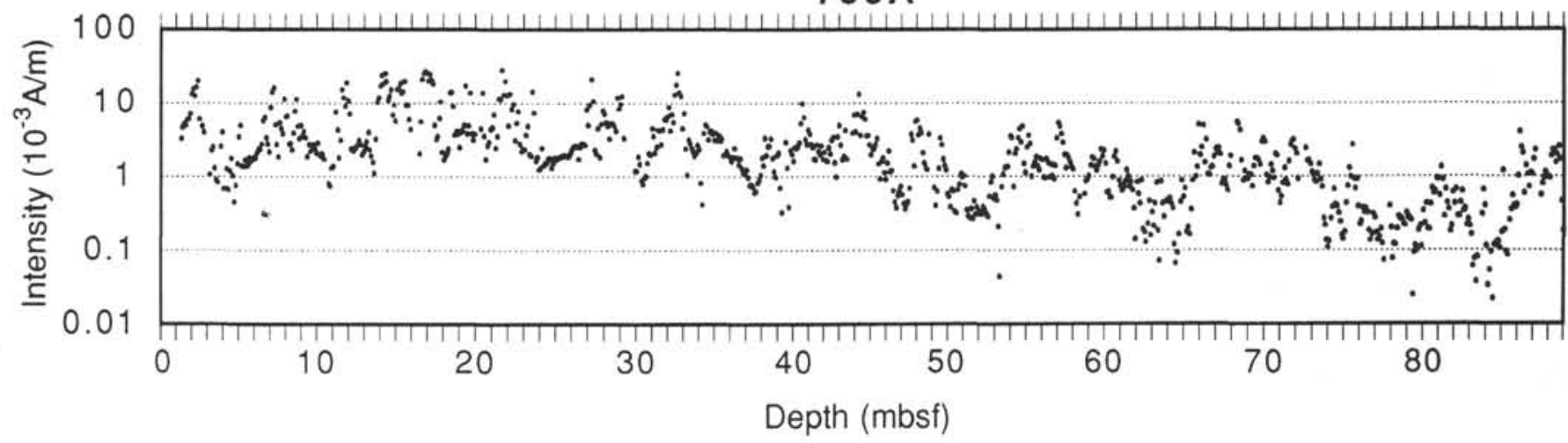

Figure 1. Variation of the magnetic intensity in the APC cores from Holes 798A, 798C, and 799A as a function of depth below seafloor. The right end at each plot corresponds to the Brunhes/Matuyama polarity boundary.

of the entire plotted section for Hole $799 \mathrm{~A}$ is $10 \mathrm{~m}$, whereas that of the plots for Holes $798 \mathrm{~A}$ and $798 \mathrm{C}$ is $27 \mathrm{~m}$. The correlation of the variation in magnetic intensity is evident. The trend of the variation of the magnetic intensity seems different, but variations with a wave length of several meters correlate well among these cores. The observed correlation among the sediment cores with different sedimentation rates by about a factor of three, confirms the validity of the depth comparison by using the intensity variation.

For the comparison of the sediment depth, variations of the directional data can also be used. However, in the present sediment cores, the variations of the inclination and the declination are dominated by much higher frequencies than that of the magnetic intensity, and are not suitable for correlating the depths in meter scale. The scatter of the directional data can be attributed to the fact that the disturbances during coring and handling the core samples mainly affect the direction of the magnetization.
Considering this difficulty, we made the present analysis in two steps. First, the depth variations of the inclination in Holes $798 \mathrm{C}$ and 799A were low-pass filtered so that the short wavelength disturbances (shorter than several meters) are smoothed out. Then, the sediment sections in two holes for the Brunhes normal Epoch were divided into five intervals as shown in Figure 4, in which the boundaries between the intervals were determined at the local minima of the smoothed variations of the inclination. As directional data, only the inclination data are used because of the ambiguity of the declination difference between the cores.

As a second step, variations of the magnetic intensity are compared in each respective interval. The variations in magnetic intensity from Holes 798C and 799A in the third interval are compared in Figure 5. At this scale, the peaks of variations with a wavelength of a few meters correlate well between these two holes, as well as the variations with a longer wavelength of a few tens of meters. In this interval, the depths of 
798A

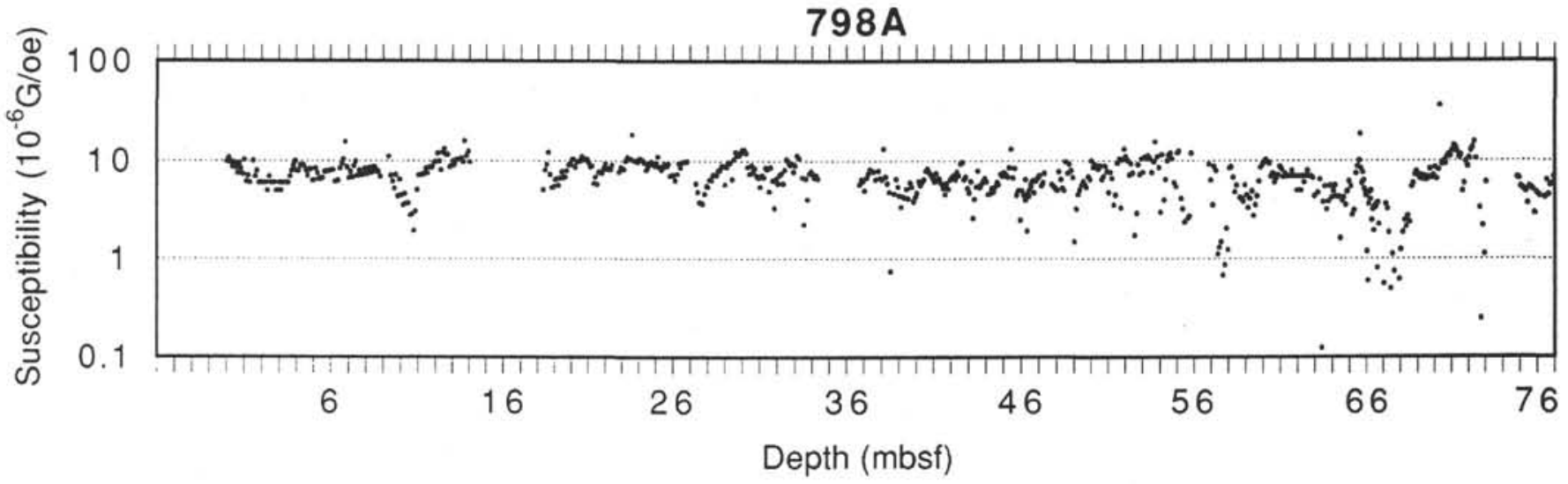

(0)

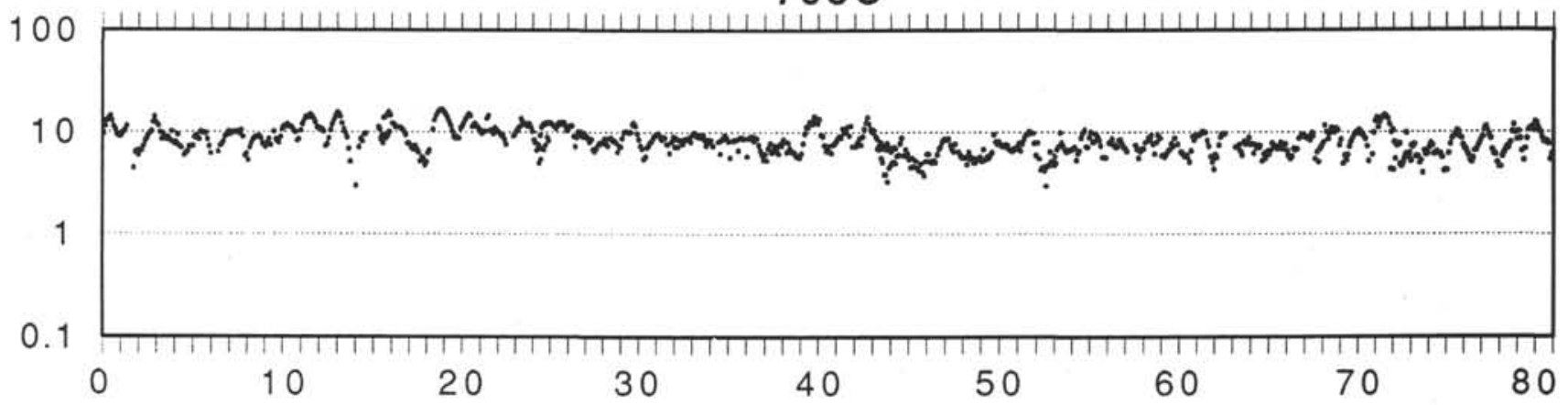

Depth (mbsf)

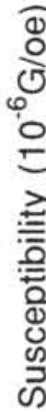

799 A

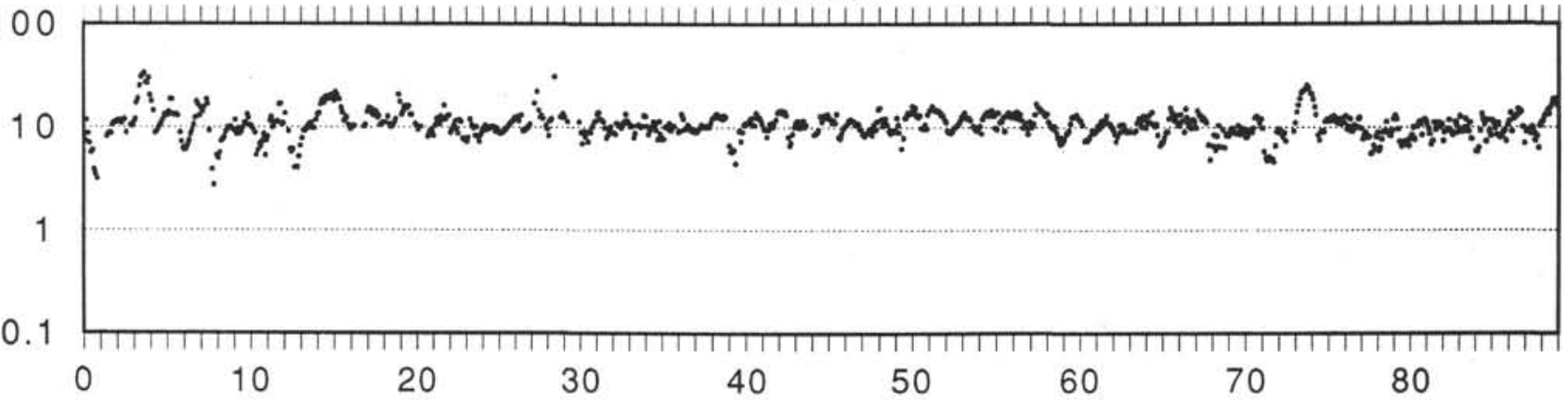

Depth (mbsf)

Figure 2. Depth plot of initial magnetic susceptibility in Holes 798A, 798C, and 799A. The depth scale is the same as Figure 1.

$33.4 \mathrm{~m}, 37.5 \mathrm{~m}, 40.5 \mathrm{~m}, 44.2 \mathrm{~m}, 46.7 \mathrm{~m}$, and $48 \mathrm{~m}$ in Hole 799A are correlated with those of $35.3 \mathrm{~m}, 39.4 \mathrm{~m}, 44 \mathrm{~m}, 49.2 \mathrm{~m}, 51.8 \mathrm{~m}$, and $53.2 \mathrm{~m}$, respectively.

These correlations were obtained in each of the five intervals of the sedimentary sections in Figure 4. The peaks and troughs of the intensity variations correlate in a comparison of Holes 798C and $799 \mathrm{~A}$, because the data from $798 \mathrm{C}$ are more continuous than that from 798A. Based on the correlations, depth relation between Holes 798C and 799A was obtained and is shown in Figure 6. The wavy nature of the plot suggests the relative variation of the sedimentation rate between the two holes. The sedimentation rate at Site 799 relative to that at Site 798 , is calculated by fitting a smooth curve to the plot in Figure 6 and then differentiating, where the sedimentation rate of Site 798 is assumed constant. Because the Brunhes/Matuyama boundary at Hole $798 \mathrm{C}$ is observed at $81 \mathrm{mbsf}$, the assumed constant sedimentation rate at Site 798 is $110 \mathrm{~m} / \mathrm{m} . \mathrm{y}$.
The relative sedimentation rate obtained at Site 799A as a function of depth at Site 798A is shown in Figure 7. During the Brunhes normal Epoch, the high sedimentation-rate peaks at Hole 799A is observed at 15-25 and 60-70 mbsf. The approximate ages of these peaks in the sedimentation rate are $0.14-0.22$ and $0.55-0.64 \mathrm{Ma}$. Another peak is suggested at the Brunhes/Matuyama boundary, although the sedimentation rate at Hole 799A before the boundary is much lower than that at Site 798. The sedimentation rate at both Sites 798 and 799 was similar during the period after $0.14 \mathrm{Ma}$. Between 0.22 and $0.55 \mathrm{Ma}$, the sedimentation rate at Site 799 was slightly lower than that at Site 798 by a ratio of about 0.7 .

By using the sedimentation rate at Site 799 relative to that at Site 798 , it is possible to obtain a calibrated depth plot of the intensity data from Site 799. The intensity variations in the magnetization at the three holes are compared in Figure 8, where the depth of the data in Hole 799A uses the calibrated depth of 


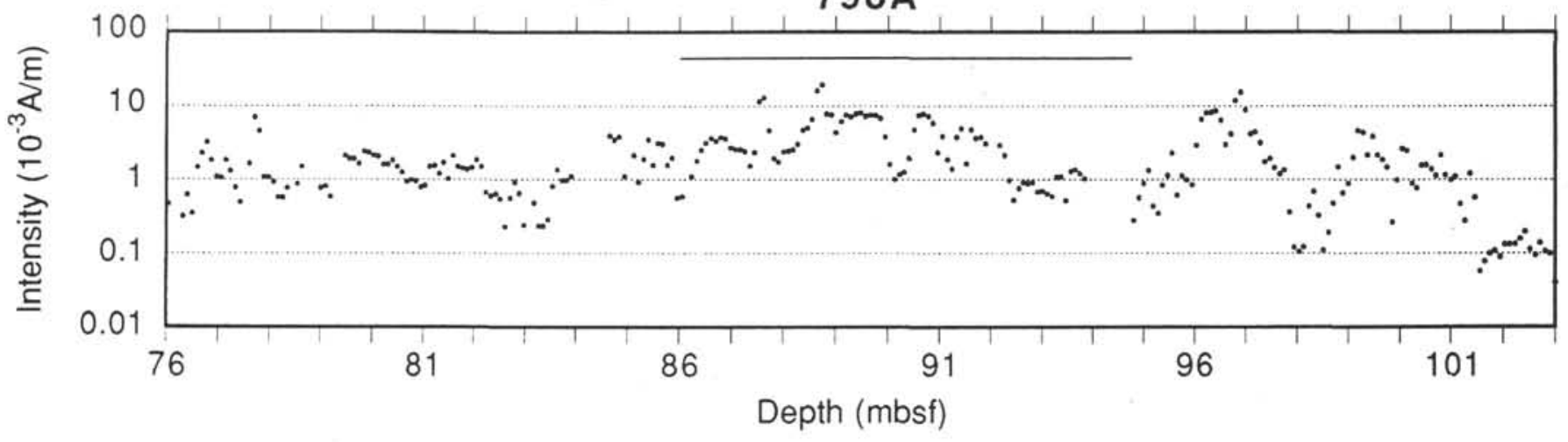

$798 \mathrm{C}$

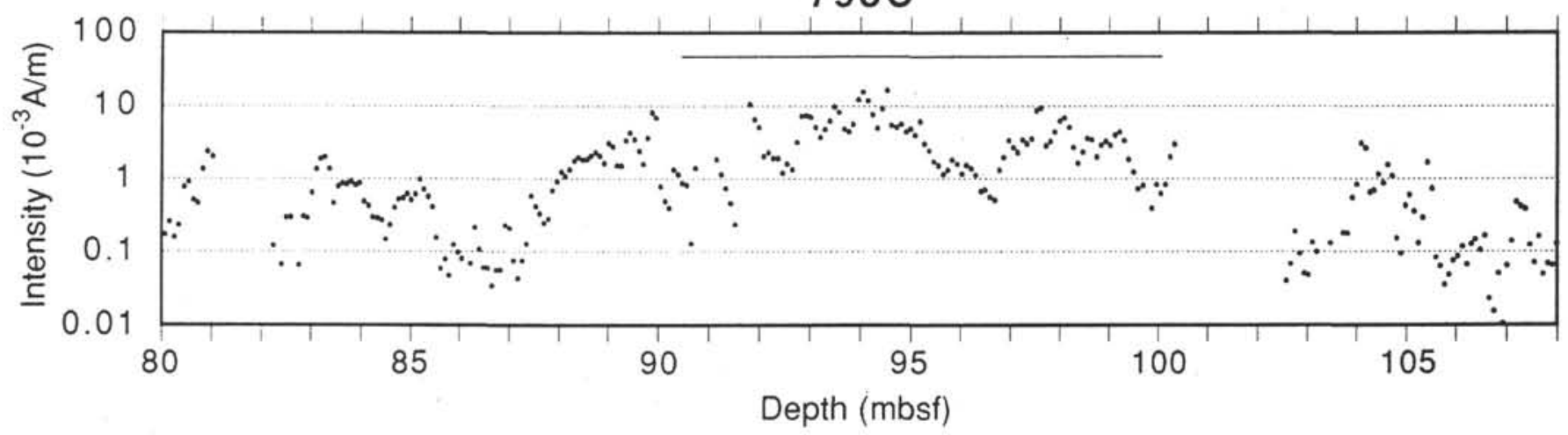

799A

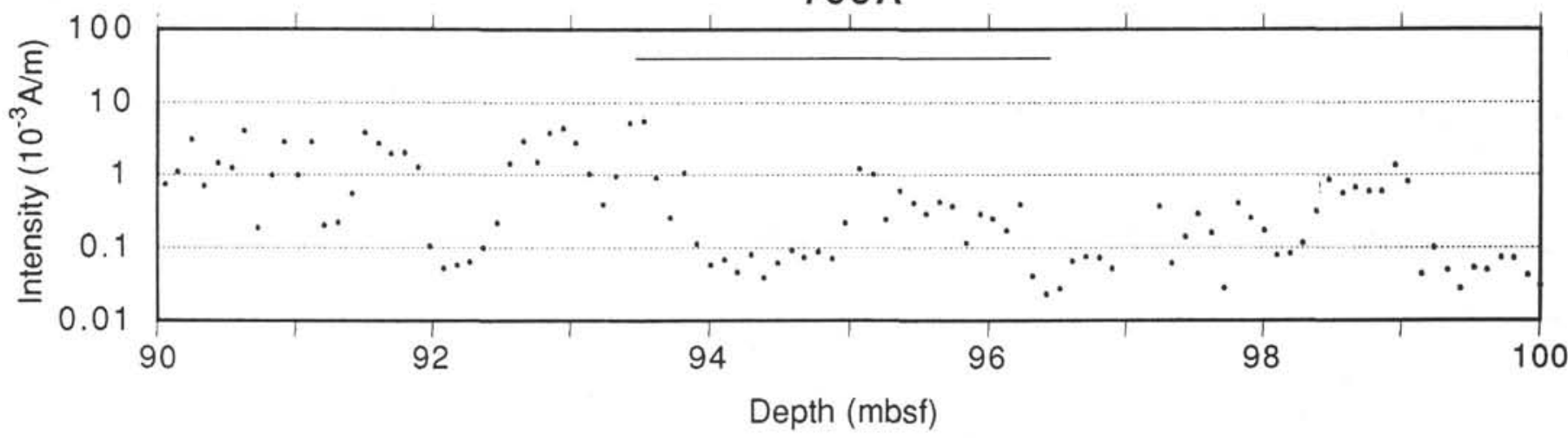

Figure 3. Magnetic intensity variations around the Jaramillo normal Event (shown by the bar) observed in the sediment cores from Holes 798A, 798C, and 799A. The horizontal scale of the bottom plot is different so that the length of the Jaramillo Event is about the same in each plot.

Site 798. As evident from Figure 8, intensity variation in the three holes is highly similar.

\section{DISCUSSION}

The similar magnetic intensity variations observed in the Leg 128 APC cores from the Japan Sea can be used to determine the detailed structure of the variation in the sedimentation rate among these sites. However, the reason for the resemblance should also be discussed.

Sites 798 and 799 are separated by more than $300 \mathrm{~km}$. Hence, the cause of the variation must be of some regional nature, at least within the Japan Sea. Changing environments in the Japan Sea, such as a change in salinity or water circulation, can be of a global nature. However, as indicated previously, the intensity variation does not correlate with the magnetic susceptibility variations. Hence, the source of the intensity variation only affected the magnetic intensity and not the magnetic susceptibility. Any sedimentary environment that affects the content of the magnetic minerals in sediments would affect both the intensity of the magnetization and the susceptibility. A change in the size distribution of magnetic particles may affect the intensity of the magnetization without changing the total amount of the magnetic mineral contents of the sediments. However, the magnetic initial susceptibility is also affected by a change in the size of magnetic particles. Generally speaking, the larger particles tend to have a larger magnetic susceptibility due to increase in the area of the magnetic domain walls. Hence, we must consider a situation in which a decreasing concentration of magnetic minerals and increasing grain diameter occur simultaneously so that the magnetic susceptibility is kept constant. This is a rather artificial situation.

Another possibility is that the intensity variations generally represent the actual variation of the intensity of the geomagnetic field. This interpretation is preferable, because the variation of the intensity 

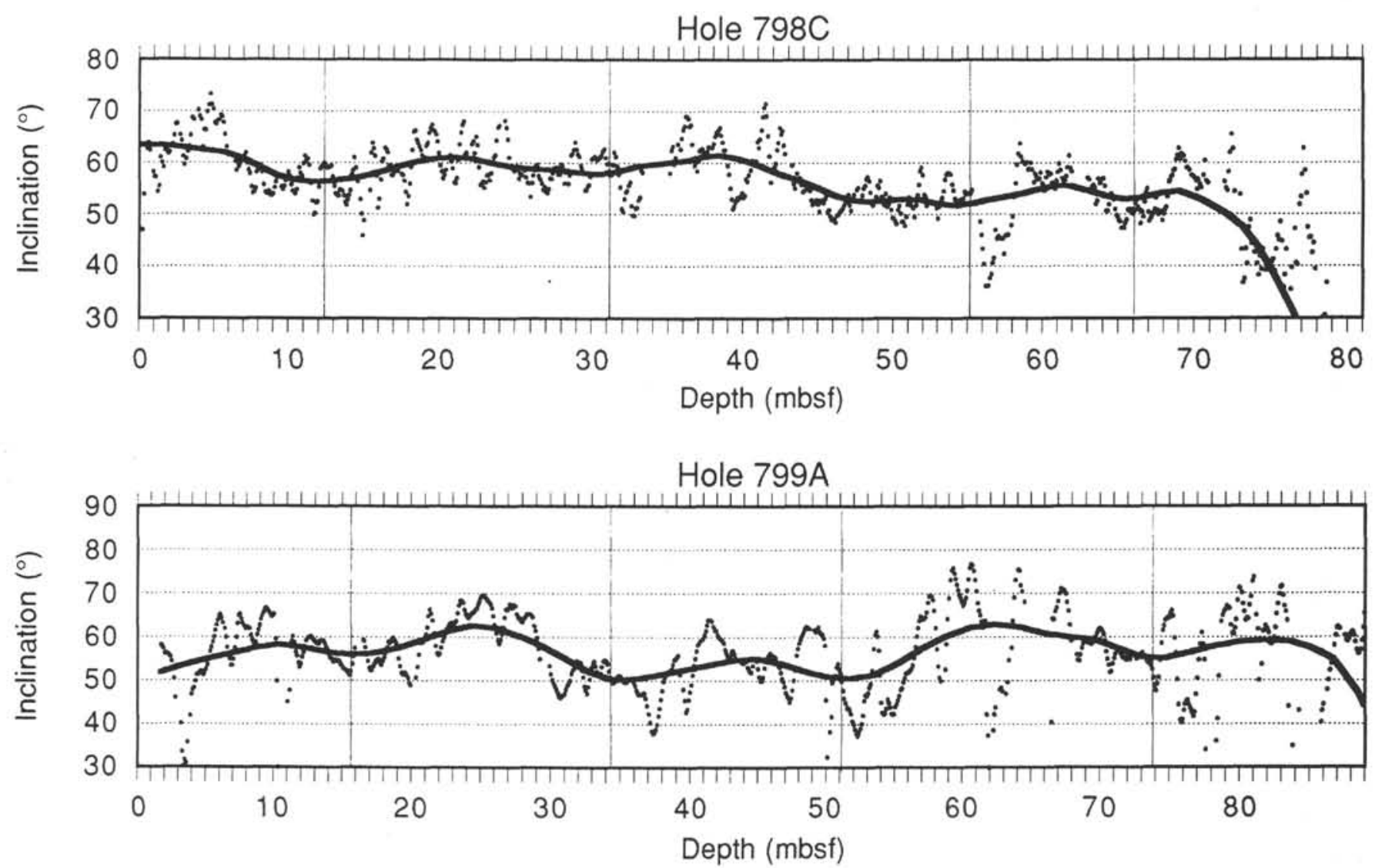

Figure 4. Variations of the inclination observed in Holes $798 \mathrm{C}$ and 799A. The low-pass filtered variations are indicated by solid curves. The five intervals shown are discussed in the text.

depends on the age of the sediments and not the depth. However, the problem with applying this interpretation is the very large scale of the variations of the magnetic intensity. The intensity variations in Figures $1,3,5$, and 8 are plotted in log scale. Hence, the variation during the last $700,000 \mathrm{yr}$ is about 2 orders of magnitude. For the short-wavelength variations, the variation is still more than 1 order of magnitude. From previous studies of the variation of the geomagnetic field, such large intensity variations are not detected. Although the continuous variation of the intensity of the geomagnetic field observed by archaeomagnetism is known only for the last $10,000 \mathrm{yr}$, the study of the statistical distribution of the paleointensity data for the last 5 m.y. suggests much a smaller variation (McFadden and McElhinny, 1982).

The mechanism of the remanent acquisition of sediments is not well known. If the intensity of the magnetization of the sediments exaggerates the variations of the geomagnetic field, the present variations of the magnetic intensity may be explained. Hamano (1983) demonstrated that magnetic interaction between magnetic particles affects the intensity of the remanence, and the effect is larger for smaller particles (higher spontaneous magnetization) and for lower concentrations of the magnetic minerals. This effect of the magnetic interaction exerts some non-linear influence on the relation between the ambient geomagnetic field intensity and the intensity of magnetization in sediments.

One other possibility for the cause of the large variation of the magnetic intensity is an offset of the magnetization measurements of the SQUID magnetometer during measurement. The directional data and the intensity data both indicate a higher scatter of the data points for lower intensity samples.
In order to clarify the cause of the intensity variations, we clearly need more investigation such as Anhysteretic Remanent Magnetization (ARM) and probably re-sedimentation experiments, which are planned. Comparison of the present data with the intensity data of sediments observed by Kent and Opdyke (1977) is also helpful (Hamano, in press).

As discussed previously, the cause of the variation of the intensity is not completely clear at present. However, the close correlation of the intensity variations among the three holes enables comparison of the sedimentation history of these cores. These data can be used to convert the depth variations of any parameters to that of age. As an example of this process, we calculated the distribution of ash layers with depth in Hole 799A. At Site 799, 137 ash layers are observed within the Brunhes normal Chron, whereas 67 ash layers are observed at Site 798. The ash layers reflect volcanic activity around the Japanese Island arc. Between the two sites, Site 798 is much closer to the region of volcanic activity than Site 799. The distribution of the ash layers between the two sites is better compared using an age plot rather than a depth plot. By using the sedimentation rate shown in Figure 7 and assuming the constant sedimentation rate at Site 798 for throughout the Brunhes normal polarity Chron, we can calculate the age variation of the volcanic ashes for Sites 798 and 799 (Fig. 9). Although the thin ash layers are more numerous at Site 799, layers thicker than $2 \mathrm{~cm}$ are more abundant at Site 798. Among the thick layers observed at Site 799, the ash layers at about $40,000,240,000,570,000$, and $710,000 \mathrm{yr}$ are observed at Site 798 , whereas the ash layers at 100,000 and 130,000 , and $700,000 \mathrm{yr}$ are not observed at $\mathrm{Site} 798$. This comparison is also useful for correlating the ash layers to volcanic activity in Japan. 
$798 C$

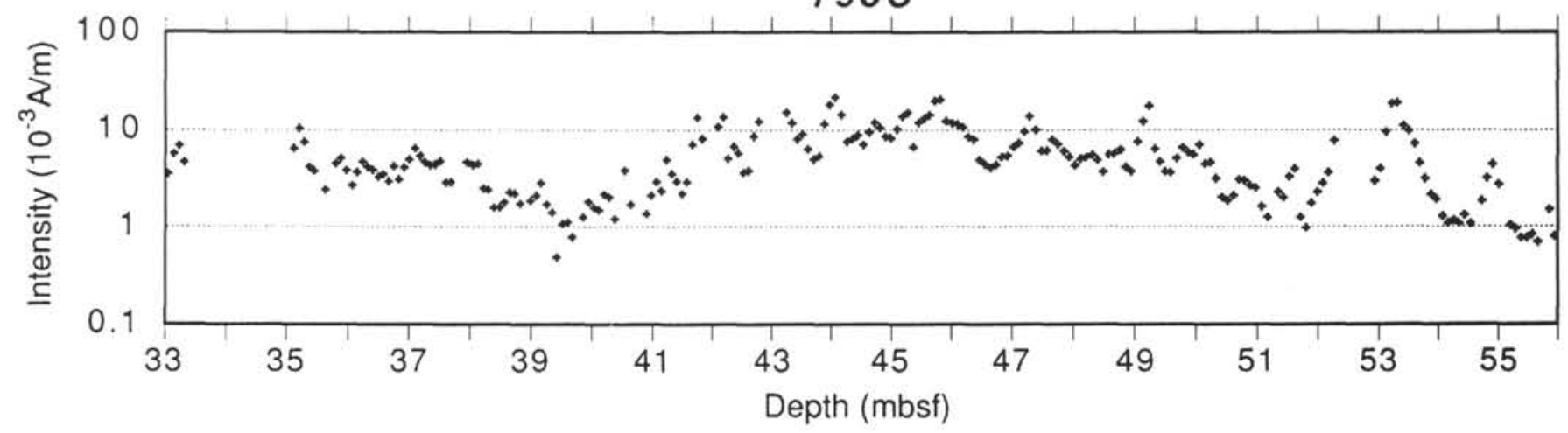

799A

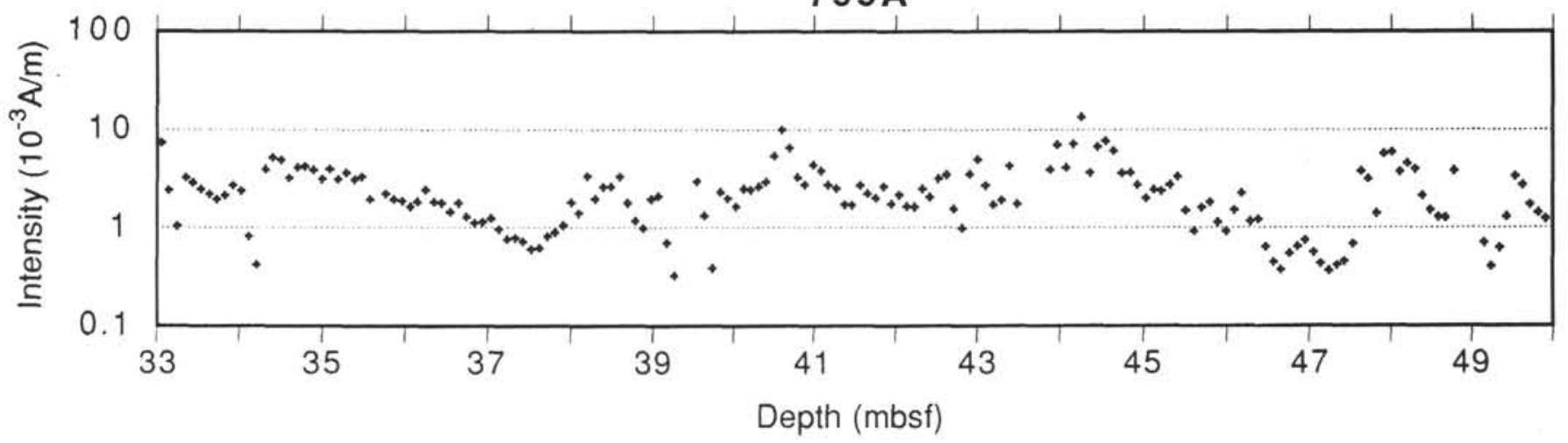

Figure 5. Comparison of the intensity variations observed in the sediment cores from Holes 798C and 799A.

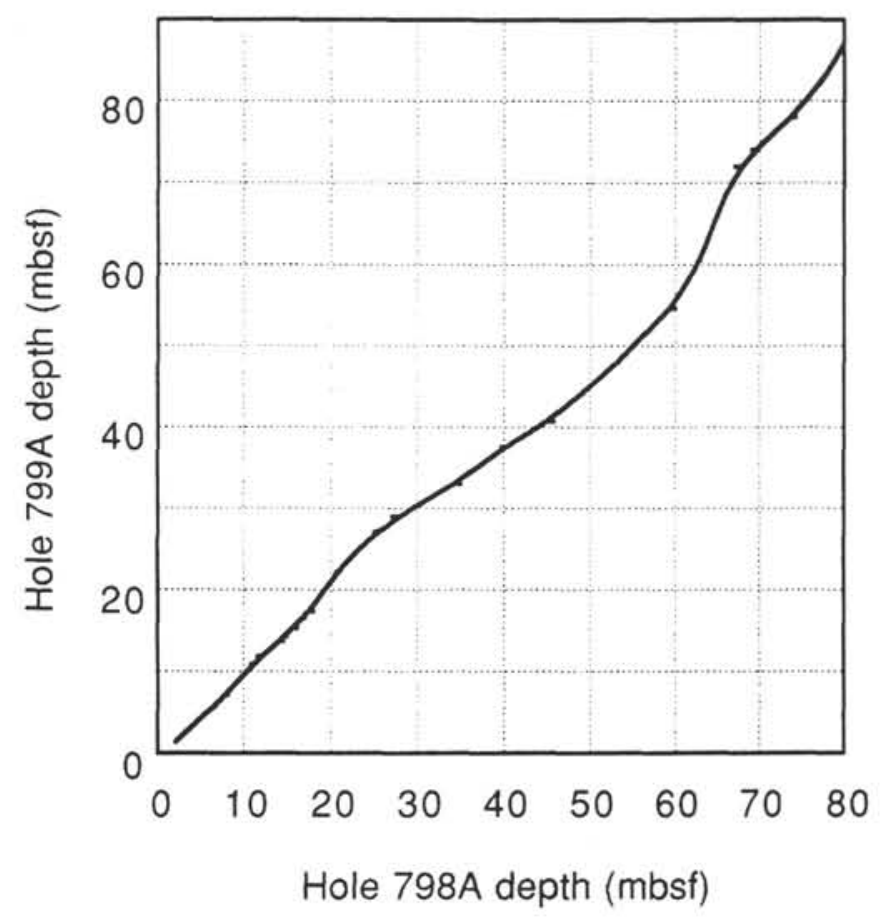

Figure 6. Comparison of the depth of the peaks and troughs observed in the intensity variations of the sediment cores from Holes 798C and 799A.

\section{REFERENCES}

Hamano, Y., 1983. Role of magnetic interaction in sediments. J. Geomagn. Geoelectr., 35:173-183.

Ingle, J. C., Jr., Suyehiro, K., von Breymann, M. T., et al., 1990. Proc. ODP, Init. Repts., 128: College Station, TX (Ocean Drilling Program).

Kent, D. V., and Opdyke, N. D., 1977. Palaeomagnetic field intensity variation recorded in a Brunhes Epoch deep-sea sediment core. Nature, 266:156-159.

McFadden, P. L., and McElhinny, M. W., 1982. Variations in the geomagnetic dipole 2: statistical analysis of VDMs for the past 5 million years. $J$. Geomagn. Geoelectr., 34:163-189.

Date of initial receipt: 29 April 1991

Date of acceptance: 11 March 1992

Ms 127/128B-214 


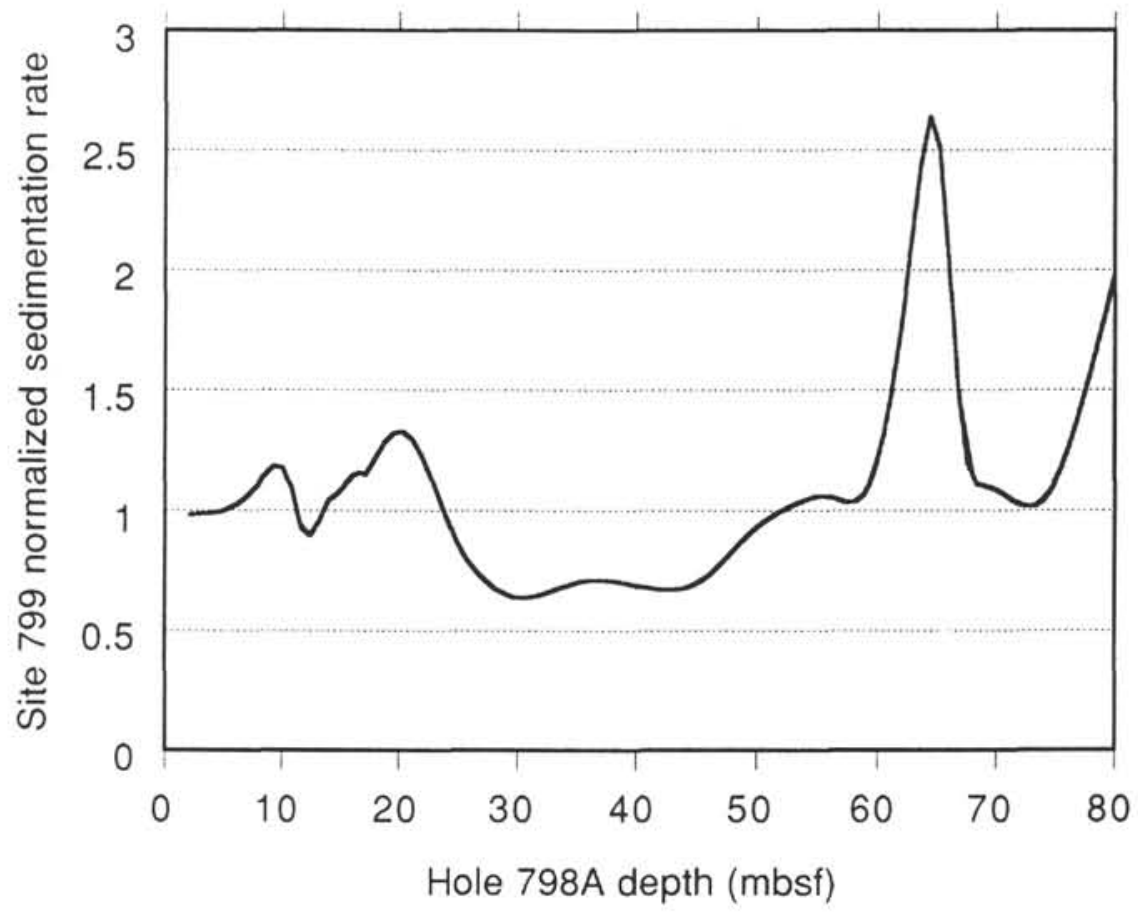

Figure 7. Sedimentation rate at Site 799 relative to that at Site 798. The rate is plotted as a function of depth of the sediments at Hole 798A. 
798A

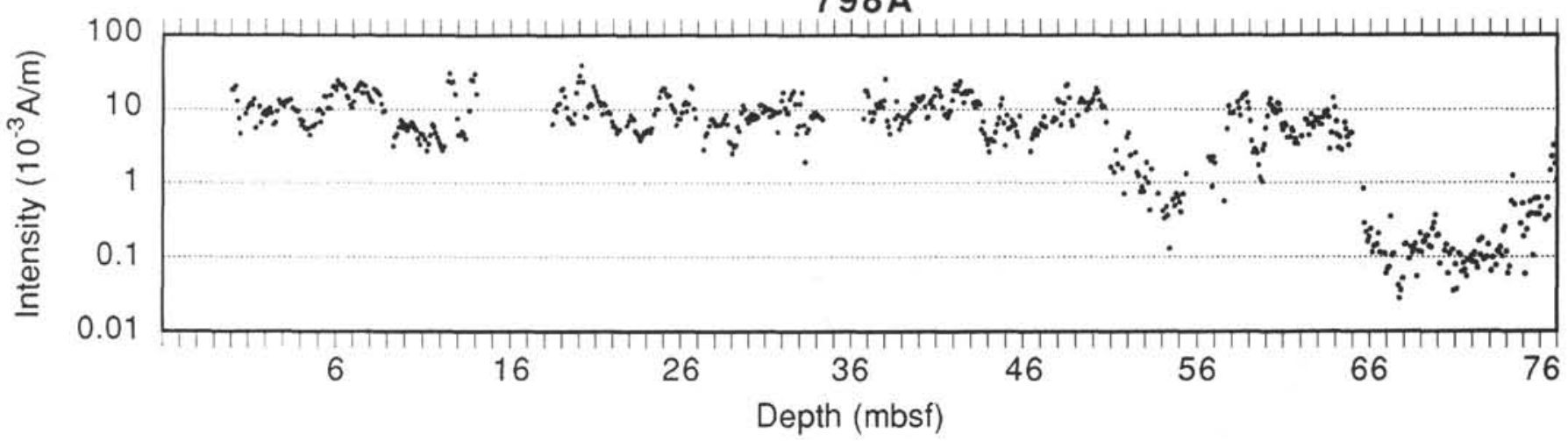

$798 \mathrm{C}$

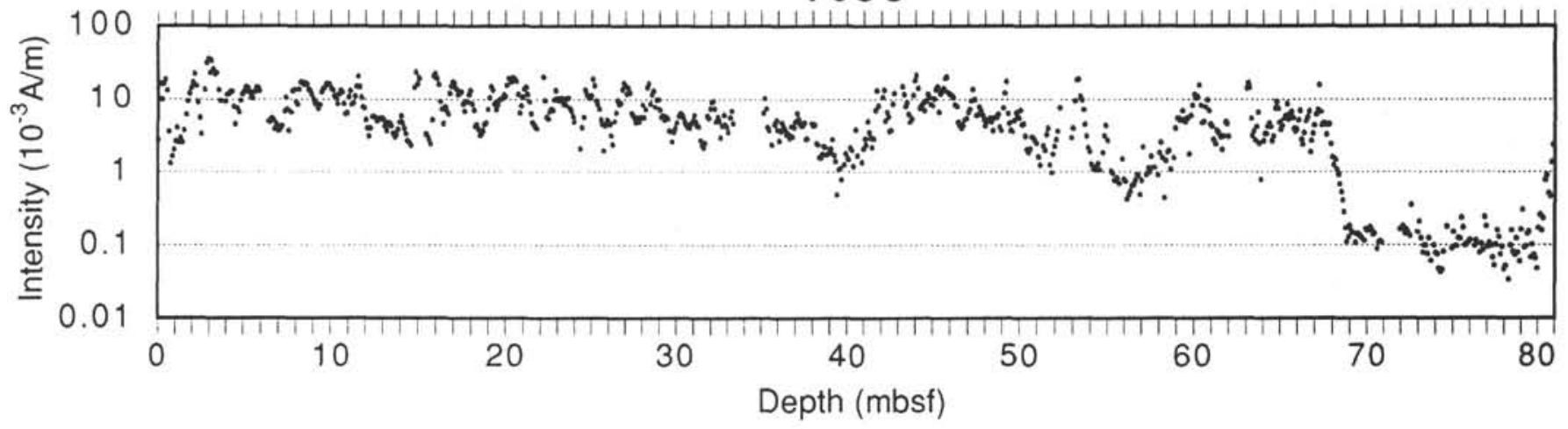

799A

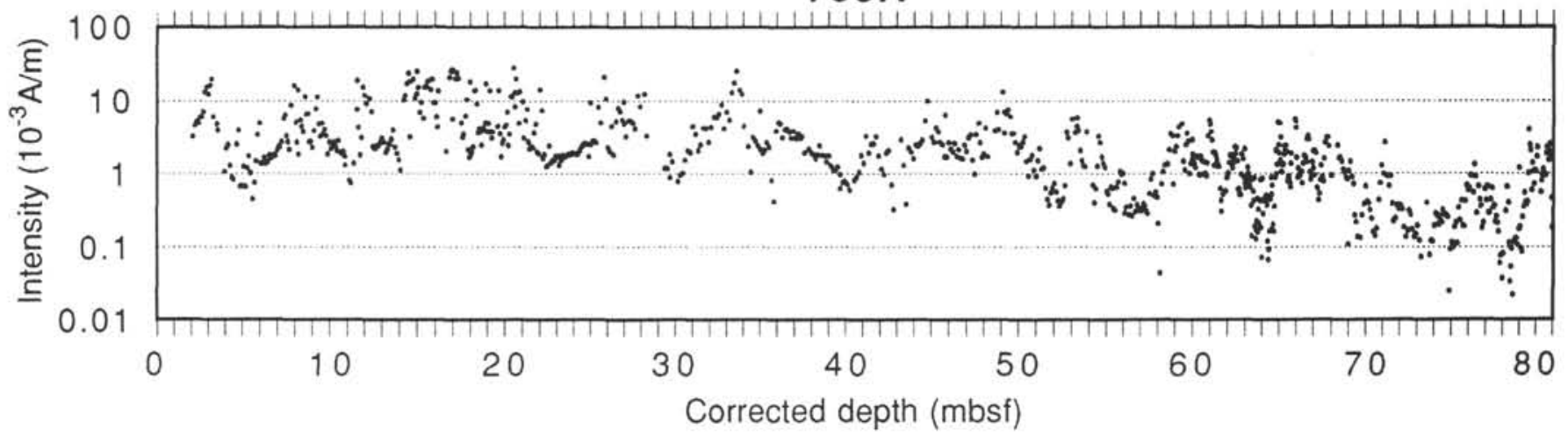

Figure 8. Comparison of the variation in magnetic intensity observed in sediment cores from Holes 798A, 798C, and 799A. The depth scale for Hole 799A is adjusted using the sedimentation rate shown in Figure 7. 
Site 798

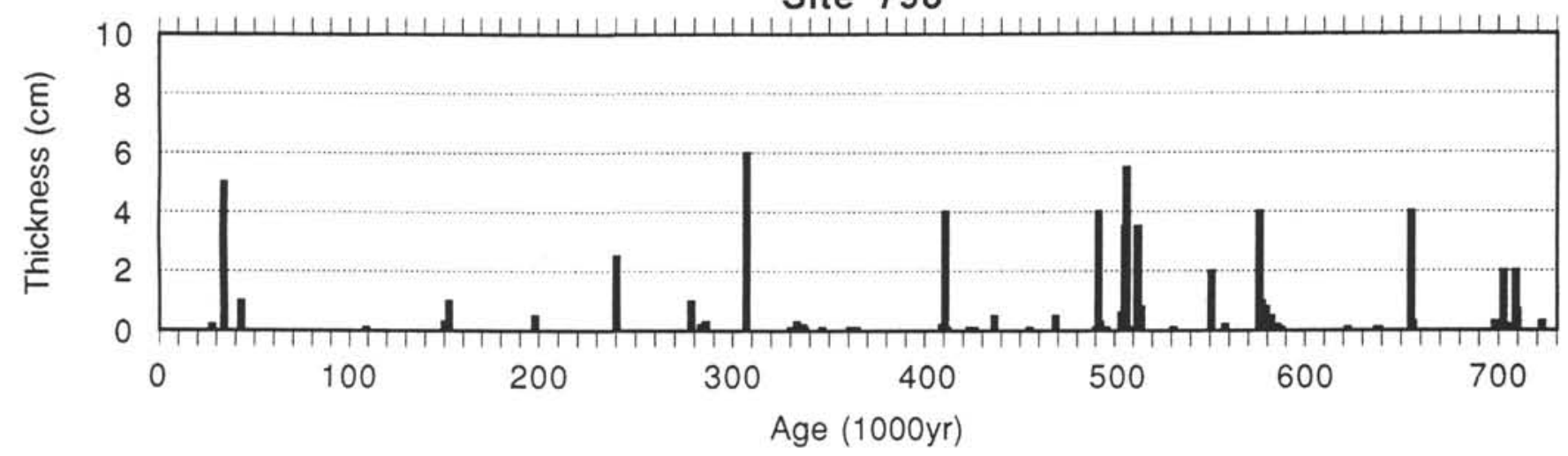

Site 799

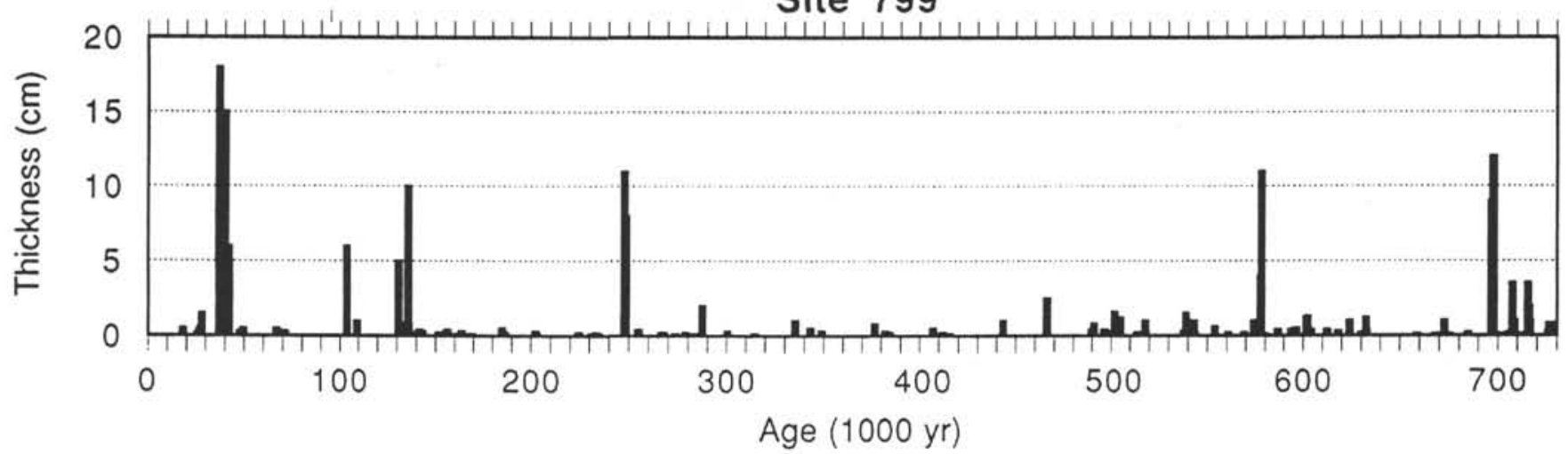

Figure 9. Comparison of observed ash layers within the Brunhes normal Chron at Sites 798 and 799 as a function of age. 